\title{
Network Relationship between Commercial Bank Liquidity Indicators and Various Indicators-Based on Bayesian Network
}

\author{
Shangde Gou ${ }^{1, a}$, Bohui Wen ${ }^{1}$ and Qingxin Kong ${ }^{1}$ \\ ${ }^{1}$ Tianjin University of Finance and Economics, China
}

\begin{abstract}
Draining liquidity is one of the main reasons for the financial crisis. Therefore, exploring the link between various indicators of banks and bank liquidity has great significance for studying bank liquidity risk. The article applies principal component to analysis the main components are extracted from the perspectives of assets,loans, deposits, borrowings and reserves. Then the Bayesian network is used to construct a network of links between liquidity and indicators based on this.
\end{abstract}

\section{Introduction}

The difficulty of liquidity recovery is one of the main reasons for triggering liquidity risk and causing banking crisis. Therefore, it's very significant to carefully process the liquidity risk of banks and to properly assess and prevent them through the link relationship between indicators. In addition, the liquidity risk of commercial banks is of great significance to the stability of the financial system (Fecht, 2004 ; Bonner, 2012) [1-2]. However, due to the inherent nature of commercial banks, liquidity risk remains one of the biggest threats facing commercial banks. Therefore, how to effectively monitor the liquidity of commercial banks has become the focus of common concern in academia and practice (Banerjee et al, 2017) [3].

From the existing facts and research, the liquidity risk of commercial banks is due to the maturity mismatch between income and expenditure (B. Holmström, J. Tirole, 1998; G.A. Vento, P. La Ganga, 2009) [4-5], The big financial crisis in history is also mostly due to the liquidity crisis in commercial banks. In this regard, the Basel Committee also revised the bank liquidity risk management and regulatory framework during the crisis cycle, The former China Banking Regulatory Commission and the current Banking Regulatory Commission have also continuously revised the Chinese regulatory system, On the one hand, it reflects the increasingly serious task of China's commercial banks' liquidity risk supervision, On the other hand, it also reflects the need to continuously improve the liquidity supervision system of Chinese commercial banks, Therefore, exploring the convergence of bank liquidity and other indicators still has positive practical significance for Chinese commercial banks.

From the study of the existing literature, the predecessors mainly use the static index method (Peter,
1996; Magnus, 2006; Chatterjee, 2015; Young, Jang, 2016) [6-9], Dynamic matching (Gianfranco, 2009; Musakwa, 2013) [10-11], Model analysis (Andreas, 2014) [12], And machine learning (Fehrer, et al 2015; Schmidhuber, 2015; Madjid et al, 2018) [13-15] to research the liquidity regulation and analysis of bank liquidity monitoring and evaluation, However, there are still few studies on application-related algorithm optimization.

The research in this paper mainly extracts the principal components from the asset class, loan class, deposit class, borrowing class and reserve fund level, and applies the hill climbing algorithm to learn the structure of Bayesian network, builds the link between liquidity and each index. Therefore, it is possible to provide advice on the monitoring and evaluation of the liquidity of the bank in terms of the link relationship of the indicators.

\section{Model construction}

This paper first extracts the principal components from the perspectives of asset class, loan class, deposit class, borrowing class and reserve fund, and then uses the hill climbing algorithm to learn the structure of various indicators of banks and bank liquidity risk indicators, Thereby obtaining a link between each comprehensive indicator and liquidity risk.

\subsection{Theoretical basis}

\subsubsection{Principal component analysis}

The principle of the main ingredient analysis is to recombine many original indicators with certain correlation into a new set of mutually independent comprehensive indicators instead of the original ones.

a Corresponding author: 15802207510@163.com 
Mathematical treatment is usually the original $\mathrm{P}$ index as a linear combination, as a new composite indicator. It is generally expressed by the variance of F1 (first principal component), that is to say, the larger $\operatorname{Var}(\mathrm{F} 1)$, the more information F1 contains. Therefore, the F1 should be the largest variance of all linear combinations. If the primary ingredient is not enough to represent the original $\mathrm{P}$, then consider the second linear combination F2, to effectively reflect the original message, the F2's information doesn't contain information about $\mathrm{F} 1$, that is, $\operatorname{Cov}(\mathrm{F} 1, \mathrm{~F} 2)=0$, By analogy, the third, fourth,..., the $\mathrm{P}$ principal components can be constructed, and the specific derivation is as follows:

For a sample set, observe $\mathrm{p}$ variables $\mathrm{x} 1, \mathrm{x} 2, \ldots \mathrm{xp}$, then the matrix of $\mathrm{n}$ samples is:

$$
X=\left\{\begin{array}{cccc}
x_{11} & x_{12} & \cdots & x_{1 p} \\
x_{21} & x_{22} & \cdots & x_{2 p} \\
\vdots & \vdots & \cdots & \vdots \\
x_{n 1} & x_{n 2} & \cdots & x_{n p}
\end{array}\right\}=\left(\begin{array}{llll}
x_{1}, & x_{2}, & \cdots & x_{p}
\end{array}\right)
$$

Principal component analysis is the synthesis of $p$ observation variables integrated into $p$ new variables (integrated variables), namely:

$$
\left\{\begin{array}{ccccc}
F_{1}= & \alpha_{11} x_{1}+ & \alpha_{12} x_{2}+ & \cdots+ & \alpha_{1 p} x_{p} \\
F_{2}= & \alpha_{21} x_{1}+ & \alpha_{22} x_{2}+ & \cdots+ & \alpha_{2 p} x_{p} \\
\vdots & \vdots & \vdots & \vdots & \vdots \\
F_{p}= & \alpha_{p 1} x_{1}+ & \alpha_{p 2} x_{2}+ & \cdots+ & \alpha_{p p} x_{p}
\end{array}\right.
$$

Abbreviated as:

$$
F_{j}=\alpha_{j 1} x_{1}+\alpha_{j 2} x_{2}+\cdots+\alpha_{j p} x_{p}, j=1,2, \cdots p
$$

The model is required to meet the following conditions:

(1) $\mathrm{Fi}, \mathrm{Fj}$ are mutually uncorrelated $(\mathrm{i} \neq \mathrm{j}, \mathrm{i}, \mathrm{j}=1,2, \ldots, \mathrm{p})$;
(2) F1 variance is greater than the variance of $F 2$, greater than the variance of $\mathrm{F}_{3}$, and so on;

(3) $\alpha_{\mathrm{k} 1}{ }^{2}+\alpha_{k 2}{ }^{2}+\cdots \alpha_{k p}{ }^{2}=1, k=1,2, \ldots, p$; Thus, $\mathrm{F} 1$ is said to be the first pricipal component, the F2 is the second main ingredient, and so on, until the pth principal component. Here $\alpha_{\mathrm{ij}}$ represents the principal component coefficient.

\subsubsection{Principal of Bayesian network}

The Bayesian network is is a structure that has a directed acyclic gram (DAG), In other words, $G=(V, E)$, where $\mathrm{V}$ represents a group of nodes and $\mathrm{E}$ represents the arc of connecting nodes. In order to accurately learn the Bayesian network structure, this paper uses the hill climbing algorithm with local advantages to learn Bayesian network structure.

In the Bayesian network, there is no directional edge between two nodes indicating that the two indicators are conditionally independent or boundary conditions. Otherwise, it indicates the dependencies between nodes. Let $\mathrm{X}$ be a set of random variables expressed by $\mathrm{V}$, and the probability distribution function of $\mathrm{X}$ is a global probability distribution function. The probability distribution of a single indicator $\mathrm{x}$ in $\mathrm{X}$ is a local probability function and exists only on a single node and its parent node $\mathrm{pa}(\mathrm{x})$. Then the global probability distribution function of $\mathrm{X}$ can be expressed as follows:

$$
\operatorname{Pr}(X)=\prod_{x \in X} \operatorname{Pr}(x \mid p a(x))
$$

In addition, the global probability distribution function and the posterior probability of $X$ are both dependent on a set of learned parameters $\Theta$, so that the posterior probability function can be expressed as follows:

Table 1. Description of indicators.

\begin{tabular}{|c|l|l|l|}
\hline $\begin{array}{c}\text { Indicator } \\
\text { number }\end{array}$ & Indicator name & Calculation method & Source of risk \\
\hline X1 & liquid assets & liquid assets / Current liabilities & Asset class \\
\hline X2 & Core capital adequacy ratio & Net core capital / Total weighted risk assets & Asset class \\
\hline X3 & ROE & Net profit accounts for the bank's share of equity capital & Asset class \\
\hline X4 & loan-to-deposit ratio & Total loans / The total deposit & Loan class \\
\hline X5 & Non-performing loan ratio & Bad loans / The loan amount & Loan class \\
\hline X6 & Loan structure indicators & Medium and long-term loan / Total loans & Loan class \\
\hline X7 & Deposit structure ratio & Demand deposit / Time deposits & Deposit class \\
\hline X8 & Deposit ratio & Deposit balance / Total assets & Deposit class \\
\hline X9 & -- & B's credit in O / Current assets & Lending category \\
\hline X10 & -- & B's credit in O / O's credit in B & Lending category \\
\hline X11 & Borrow capital ratio & Unpacking funds / Deposit balance & Lending category \\
\hline X12 & Capital ratios & Withdrawal of funds / Deposit balance & Lending category \\
\hline X13 & Reserve ratio & $\begin{array}{l}\text { (Deposit central bank payments + cash in stock) / Various } \\
\text { deposits }\end{array}$ & Reserve class \\
\hline X14 & Provision coverage & $\begin{array}{l}\text { General preparation + Specific provisions + Special } \\
\text { preparation)/ (sub-prime loan + loanable loan + loss loan)) }\end{array}$ & Reserve class \\
\hline X15 & Excess reserve ratio & $\begin{array}{l}\text { (Central bank's excess reserve deposit + cash in stock) / } \\
\text { Various deposits }\end{array}$ & Reserve class \\
\hline X16 & Liquidity risk & 1- Current assets / Current liabilities & Liquidity risk \\
\hline
\end{tabular}

Note: B stands for "Bank under evaluation" and O stands for "Other Banks" 


$$
\operatorname{Pr}_{G}(\theta \mid \text { Data })=\frac{\operatorname{Pr}_{G}(\text { Data } \mid \theta) \operatorname{Pr}(\theta)}{\operatorname{Pr}(\text { Data })}
$$

This paper will extract more than $80 \%$ of the main components from various indicators, and build a network of links between various categories of indicators and liquidity risk based on this comprehensive indicator. Therefore, it is possible to provide advice on the regulation of bank liquidity from the mutual influence between indicators.

\subsection{Selection of indicators}

Based on the existing literature and the liquidity measurement standard of Basel III , and combined with the liquidity supervision practice and rules of Chinese commercial banks, this paper comprehensively selects the

Table 2. Principal component results

\begin{tabular}{|c|c|c|c|c|c|c|c|}
\hline Asset 1 & Asset 2 & loan1 & loan2 & deposit & Borrowing1 & Borrowing2 & Reserve \\
\hline 2.39 & 0.47 & 2.21 & 0.75 & 1.63 & 2.5 & 1.04 & 2.45 \\
\hline $79.69 \%$ & $15.54 \%$ & $73.62 \%$ & $24.99 \%$ & $81.68 \%$ & $64.03 \%$ & $25.92 \%$ & $81.72 \%$ \\
\hline 1.3349 & -1.4621 & -2.3339 & 2.1806 & 1.8874 & -2.2166 & -1.825 & -0.2378 \\
\hline 1.3174 & -1.8633 & -2.0205 & 1.3828 & 2.2532 & -2.3901 & -1.0734 & -0.155 \\
\hline 1.5219 & -1.5837 & -2.6659 & 1.6044 & 2.1527 & -2.7471 & -0.5166 & 0.4099 \\
\hline 0.468 & -0.9872 & -2.0324 & 1.0178 & 2.6701 & -3.1398 & -0.7701 & 0.8939 \\
\hline 2.1968 & -0.4841 & -2.2415 & 0.7062 & 2.0954 & -2.2632 & -0.2158 & 1.3586 \\
\hline 2.5003 & 0.15 & -1.9515 & 0.1422 & 2.119 & -2.0833 & -0.0908 & 1.6084 \\
\hline 1.9105 & -0.0309 & -1.4792 & -0.3644 & 1.9274 & -1.794 & -0.1557 & 2.1472 \\
\hline 0.9681 & -0.1156 & -1.0827 & -0.56 & 1.5938 & -1.4466 & -0.2965 & 1.6378 \\
\hline 1.9532 & 0.2333 & -0.8545 & -1.046 & 0.72 & -0.9256 & -0.7803 & 1.7759 \\
\hline 1.9842 & 0.8025 & -0.6895 & -1.3709 & 0.2233 & -0.9465 & -0.1345 & 1.5716 \\
\hline 1.754 & 0.8125 & -1.3325 & -0.6366 & 0.0737 & -1.2432 & -0.1517 & 1.7246 \\
\hline 0.8445 & 0.7174 & -1.0666 & -0.8948 & 0.0571 & -1.0771 & -0.06 & 2.5857 \\
\hline 1.1665 & 0.6973 & -0.9092 & -0.9786 & -0.4907 & -0.3305 & 0.8893 & 1.4557 \\
\hline 1.0013 & 0.4448 & -0.6638 & -1.173 & -0.5848 & -0.3676 & 1.6679 & 1.4681 \\
\hline 1.0044 & 0.3731 & -0.6776 & -0.8881 & -0.5253 & -0.6753 & 1.966 & 1.1758 \\
\hline 0.3194 & 0.2296 & -0.1739 & -1.1115 & -0.6188 & 0.0282 & 2.0537 & 0.973 \\
\hline 0.9459 & 0.3491 & -0.1534 & -0.86 & -0.7059 & 0.3547 & 1.2341 & 1.0491 \\
\hline 0.5832 & 0.5544 & -0.0614 & -1.0722 & -0.5633 & 0.525 & 1.665 & 0.8477 \\
\hline 0.2348 & 0.8396 & 0.1615 & -0.6742 & -0.6925 & -0.4312 & 1.038 & 0.2803 \\
\hline-0.8308 & 0.9755 & 0.4611 & -0.6603 & -1.3702 & 0.5637 & 1.2358 & 0.5717 \\
\hline-0.5496 & 0.677 & 0.5885 & -0.0209 & -1.6102 & 1.4364 & 0.2304 & -0.1979 \\
\hline-0.8446 & 0.6505 & 1.0609 & -0.0321 & -2.0146 & 2.0227 & -1.5952 & 0.2192 \\
\hline-1.4298 & -0.0024 & 1.1832 & 0.1082 & -1.5584 & 1.9133 & -0.8069 & -1.48 \\
\hline-2.5525 & -0.2221 & 1.63 & 0.2069 & -1.4291 & 2.3015 & -1.7206 & -1.7024 \\
\hline-1.7778 & 0.0267 & 1.8684 & 0.873 & -1.1271 & 1.8728 & -0.8844 & -1.6054 \\
\hline-1.8059 & -0.0616 & 1.6302 & 0.3303 & -0.8039 & 1.7689 & -1.4337 & -1.5491 \\
\hline-1.9354 & 0.009 & 2.0072 & 0.5605 & -0.5825 & 1.7689 & -0.3171 & -2.2695 \\
\hline-2.4298 & -0.0167 & 1.5348 & 0.8038 & -0.6349 & 1.8369 & -0.7694 & -1.6848 \\
\hline-1.4448 & -0.2022 & 2.0525 & 0.431 & -0.6852 & 1.444 & 0.4907 & -2.3534 \\
\hline-1.2558 & -0.2498 & 1.5172 & 0.434 & -0.6279 & 1.2022 & 0.0805 & -2.3171 \\
\hline-1.3893 & -0.4882 & 1.9732 & 0.3524 & -0.4184 & 1.5013 & 0.6677 & -2.5502 \\
\hline-2.3291 & 0.0724 & 1.4614 & 0.6005 & -0.2556 & 1.1289 & 0.2859 & -1.8055 \\
\hline-1.7844 & -0.4986 & 1.8183 & 0.2996 & -0.1482 & 1.2186 & 0.1498 & -2.2809 \\
\hline-1.6496 & -0.3462 & 1.4417 & 0.3095 & -0.3257 & 1.1897 & -0.057 & -1.5654 \\
\hline
\end{tabular}


following 16 representative indicators as the research object of Bayesian network. As shown in Table 1 (where the liquidity risk is calculated according to Madjid's article). On this basis, weigh the availability and comparability of data. This paper selects the data of ICBC from the first quarter of 2010 to the second quarter of 2018 as a research sample.

\section{Empirical results and analysis}

\subsection{Extract the main component}

In order to make the comprehensive index have a high explanatory power, this paper extracts more than $80 \%$ of the main components from the indicators of assets, loans, deposits, borrowings and reserves. As shown in Table 2, this paper extracts two principal components in the asset index, the contribution rate of the components is $95.23 \%$,two main components in the loan index, the contribution rate of the components is $98.61 \%$,one principal components in the deposit index. the contribution rate of the components is $81.68 \%$. Two principal components in the loan-receiving index, and the cumulative contribution rate is $89.95 \%$. And one principal component was extracted from the reserve index, and the contribution rate is $81.72 \%$.

\subsection{Bayesian network construction}

After extracting the main components, this paper uses the hill climbing algorithm to carry out structural learning on the extracted comprehensive indicators and liquidity risk indicators, and obtains the figure 1 . As can be seen from the figure, the interaction between the various comprehensive indicators is related. For liquidity risk, liquidity risk will directly affect the lending and loan indicators, which is in line with common sense. However, from the perspective of the impact of liquidity risk, only the second principal component of the asset class (15.54\% contribution rate) affects the liquidity risk. That is to say, the occurrence of liquidity risk is the result of a small number of factors, of course, these factors contain information on each asset class indicator. But comparing the Bayesian network diagram of the original indicator with the liquidity risk, we can find that the asset class indicator does not directly affect the liquidity risk. Therefore, it can be explained that although a single indicator alone cannot affect liquidity risk, the combination will have an impact on liquidity risk. In addition, it can be seen from the figure that there is no comprehensive indicator that can directly affect the second type of indicators of the asset class. Combined with the Bayesian network diagram of the original indicator and the liquidity risk, we find that there are two loan indicators (LDR and loan structure indicators) and a deposit-type indicator (deposit ratio) have an impact on liquidity risk, Combining the two sets of results, we can see that although the factors directly affecting the liquidity risk are limited, there are many categories involved. Therefore, when monitoring the liquidity risk, it is necessary to reasonably control all kinds of indicators within a reasonable range to avoid and reduce the probability of occurrence of fewer risk factors.

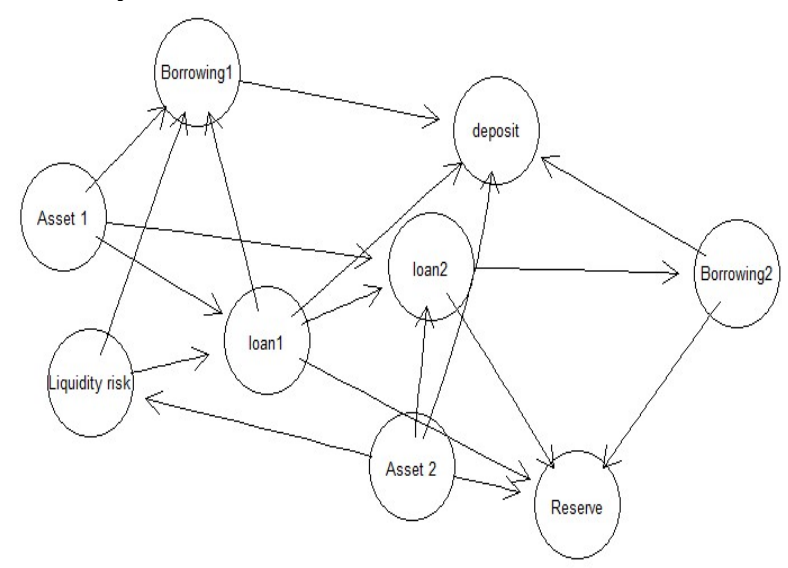

Figure 1. The network of indicators and bank liquidity risk.

\section{Conclusion}

The supervision of liquidity risk has always been the main problem faced by Banks. How to keep the liquidity risk within a reasonable range is the main challenge faced by Banks at present. This paper applies the principal component method extracts two principal components in the asset index, the contribution rate of the components is $95.23 \%$, two main components in the loan index, the contribution rate of the components is $98.61 \%$, one principal components in the deposit index. the contribution rate of the components is $81.68 \%$. Two principal components in the loan-receiving index, and the cumulative contribution rate is $89.95 \%$. And one principal component was extracted from the reserve index, and the contribution rate is $81.72 \%$. Based on the comprehensive indicator, we build a network of links between various types of indicators and liquidity risks. Combining the Bayesian network between the original indicators, the paper draws the following conclusions: (1) Liquidity risk will directly affect asset class, borrowing index and loan index; (2) The occurrence of liquidity risk is the result of a small number of comprehensive indicators (the second type of asset-based indicators) and some individual indicators; (3) There is no comprehensive indicator that can directly affect the second type of indicators of the asset class, but it will be affected by other factors in terms of the loan-to-deposit ratio and the deposit ratio that directly affect the liquidity risk. Therefore, the regulatory authorities should reasonably control various indicators within a reasonable range to avoid and reduce the probability of occurrence of fewer risk factors.

\section{Acknowledgement}

This research was financially supported by the MOE (Ministry of Education in China) Project of Humanities and Social Sciences (Grant No. 16YJAZH060); Supported by China Postdoctoral Science Founda- tion No.58 (Grant No.2015M581295); Supported by Special 
Foundation of China Postdoctoral Science Foundation (Grant No. 2017T100154); Supported by Special Program of talents Development for Excellent Youth Scholars in Tianjin (Grant No. TJTZJH-QNBJRC-2-25); Supported by 2017 "131" innovative talents training project first level candidates.

\section{References}

1. Fecht, F. J EUR ECON ASSOC, 2(6): 969-1014 (2004).

2. C Bonner, papers. ssrn. com, (2012).

3. Ryan N. Banerjee, Hitoshi Mio. J FINANC INTERMED, 35: 30-44(2017).

4. B. Holmström, J. Tirole. J POLIT ECON,1: 140(1998).

5. G.A. Vento , P. La Ganga , Money Invest. Bank. 10:78-125(2009).
6. Peter S Rose. Irwin: The MeGram-Hill Company(1996).

7. Magnus Saxegaard. IMF Working Paper (2006).

8. Ujjal K. Chatterjee. J FINANC STABIL, 18:139153 (2015).

9. Robert De Young, Karen Y. Jang. J BANK FIANC, 66: 143-161(2016).

10. G.A. Vento, P. La Ganga . Money Invest. Bank. 10:78-125(2009).

11. F.T. Musakwa, pdfs.semanticscholar.org (2013).

12. Andreas A. Jobst. J BANK FIANC.45: 270287(2014).

13. Fehrer R., Feuerriegel S.. ECIS 2016 (2016).

14. Schmidhuber J.. Neural Networks,61: 85-117(2015).

15. Tavana, M., et al...Neurocomputing. 275: 25252554(2018). 